\title{
Large variability in continental shelf production of phytoplankton carbon revealed by satellite
}

\author{
B. F. Jönsson ${ }^{1}$, J. E. Salisbury ${ }^{2}$, and A. Mahadevan ${ }^{1}$ \\ ${ }^{1}$ Department of Earth Sciences, Boston University, Boston, Massachusetts, USA \\ ${ }^{2}$ Institute for the Study of Earth, Oceans, and Space, University of New Hampshire, Durham, New Hampshire, USA \\ Received: 15 November 2010 - Published in Biogeosciences Discuss.: 10 December 2010 \\ Revised: 29 March 2011 - Accepted: 11 April 2011 - Published: 19 May 2011
}

\begin{abstract}
We estimate the net production of phytoplankton in the Gulf of Maine (GoM) over a 3-yr period using satellite ocean color data in conjunction with surface velocities from a high-resolution operational ocean circulation model. Chlorophyll (Chl- $a$ ) and light attenuation $\left(K_{490}\right)$ products are combined with a carbon to chlorophyll model to estimate the phytoplankton carbon (PC) stock in the euphotic layer. A satellite-based productivity, termed $\mathrm{NCP}_{\mathrm{e}}$ in analogy with net community production (NCP), is derived by tracking changes in satellite-derived PC from one satellite image to the next, along water parcel trajectories calculated with surface velocities from the ocean circulation model. Such an along-trajectory analysis of satellite data discounts the effect of advection that would otherwise contribute to the temporal change between consecutive images viewed in the fixed reference frame. Our results show a high variability of up to $\pm 500 \mathrm{mg} \mathrm{C} \mathrm{m}^{-2} \mathrm{~d}^{-1}$ in $\mathrm{NCP}_{\mathrm{e}}$ on spatial scales of $10-100 \mathrm{~km}$. A region-wide median $\mathrm{NCP}_{\mathrm{e}}$ of $40-50 \mathrm{mg} \mathrm{C} \mathrm{m}^{-2} \mathrm{~d}^{-1}$ is often prevalent in the Gulf, while blooms attain peak values of $400 \mathrm{mg} \mathrm{C} \mathrm{m}^{-2} \mathrm{~d}^{-1}$ for a few days. The spatio-temporal variability of $\mathrm{NCP}_{\mathrm{e}}$ in this region, though conditioned by seasonality, is dominated by events lasting a few days, which if integrated, lead to large inter-annual variability in the annual carbon budget. This study is a step toward achieving synoptic and time-dependent estimates of oceanic productivity and NCP from satellite data.
\end{abstract}

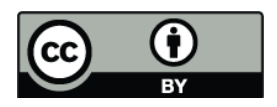

Correspondence to: B. F. Jönsson (bjonsson@princeton.edu)

\section{Introduction}

The continental shelves pose a major conundrum in our understanding of the oceanic carbon cycle. While comprising just about $7 \%$ of the global ocean, they account for up to $30 \%$ of oceanic primary production (Gattuso et al., 1998). Hence their contribution to the global carbon cycle in terms of net carbon fixation, export of particulate organic carbon (POC), air-sea flux of carbon dioxide $\left(\mathrm{CO}_{2}\right)$, and modulating the exchange of carbon between continents and oceans has been the focus of a number of recent regional studies. While some studies report a strong net source of $\mathrm{CO}_{2}$ to the atmosphere from the coastal zone (Cai et al., 2003; Frankignoulle et al., 1998; Borges and Frankignoulle, 2002; Arthur and Borges, 2009), others report that coupled biophysical mechanisms sequester globally significant amounts of atmospheric carbon (Tsunogai et al., 1999; Kortzinger, 2003; Arthur and Borges, 2009). These measurements suggest large variability in the magnitude and sign of the net community production rate in coastal environments. Our objective is to gain a synoptic understanding of this variability. What are the spatial and temporal scales of variability in coastal systems? Are the modulations in the system driven by local events or by seasonal changes? What is the influence of the coast? Is there a persistence in the spatial patterns?

In this study, we use a new approach for addressing some of these questions with satellite data. Since the advent of the NASA Coastal Zone Color Scanner in 1978, we have had the ability of assessing various indices of phytoplankton biomass using ocean color data, but estimating rates of change of biomass (e.g. net primary production - NPP) from these data has proven challenging. One difficulty lies in using individual satellite images, which can only estimate stocks or state variables. To estimate a rate of change, one must assume that the satellite data taken at a single instant

Published by Copernicus Publications on behalf of the European Geosciences Union. 
in time (e.g. photosynthetically available radiation, chlorophyll, sea surface temperature) can convey sufficient information about photosynthetic parameters and/or community structure (Behrenfeld and Falkowski, 1997). An alternative approach to retrieving rate information would be to use time series of satellite data to estimate differences in biological stocks over time, as has been done by e.g. Behrenfeld (2010) and Zhai et al. (2008). But, ocean color data is frequently interrupted by clouds and finding a sequence of images for the same region within a few days of each other can be a challenge. A second, more fundamental, issue is that water parcels are in motion and thus sequential images analyzed at a fixed location are not likely to be tracking the same water parcel. While phytoplankton growth can lead to a doubling of biomass in days, advection by horizontal velocities near the surface can contribute as much, or more, to observed variations in biomass. This makes it difficult to diagnose phytoplankton growth from subsequent satellite views of the biomass distribution, i.e., from observing temporal changes alone. To overcome this difficulty, we cast the information from sequential satellite observations within the frame of moving water parcels using a physical circulation model. We thereby track the phytoplankton biomass along water parcel trajectories to estimate a net rate of production.

Net community production (NCP) is the net rate at which carbon is fixed by autotrophy, minus that which is lost due to heterotrophic processes, and reflects the net biological modulation of the surface carbon pool. It translates into a biological drawdown or release of dissolved inorganic carbon (DIC), which alters the partial pressure of $\mathrm{CO}_{2}\left(p \mathrm{CO}_{2}\right)$ in the sea surface and thus affects the air-sea flux of $\mathrm{CO}_{2}$. Methods of estimating NCP in situ are typically based on the time evolution of organic carbon or oxygen. These include the tracking of organic particle stocks (Marra et al., 1993; Langdon et al., 1995) and light bottle oxygen incubations, in which it is assumed that carbon is related stoichiometrically to oxygen (Williams and Purdie, 1991). More recently, NCP has been estimated via the simultaneous tracking of oxygen and an inert gas (e.g. Ar) to resolve the net biological perturbation of the oxygen stock (e.g. Craig and Hayward, 1987; Kaiser et al., 2005), which registers both the fixation and respiration of organic carbon irrespective of its form. However, for the accurate analyses of depth integrated NCP, one must contend with the difficulty of quantifying the exchange of oxygen across the air-sea interface and through the base of the mixed layer. By comparison, NCP estimates based on dynamic changes in particulate organic carbon (POC) stocks are perhaps more straightforward, but do not account for dissolved components of the organic carbon pool, which could have a significant role in certain regions (Hopkinson and Vallino, 1995). While POC can be fluxed below the mixed layer, it is not subject to air-sea exchange, nor solubility effects. But most significantly, it is the ability of remotely detecting POC stocks from space that makes it attractive to use POC-based measures for NCP. We note from the onset though, that these measures may differ somewhat from the oxygen-based estimates for the reasons discussed above.

Our objective is to quantify the NCP of a coastal region and to examine its variability in space and time using satellite data. POC is comprised of several forms of particulate carbon including living (phytoplankton) and non-living (detrital) matter (Behrenfeld and Boss, 2003). Our approach is to track phytoplankton carbon (PC), or that component of the POC pool associated with living phytoplankton and assume that the net growth (production minus respiration and grazing) of PC represents NCP. We track the evolution of satellite-derived PC while accounting for its horizontal movement by surface velocities. We budget for PC over the euphotic depth, assuming that the satellite estimate represents a euphotic-depth average, and that any vertical export of PC can be accounted as a loss because it must be respired beneath.

We apply this approach to the Gulf of Maine, a highly productive, semi-enclosed basin situated between $42^{\circ} \mathrm{N}$ and $46^{\circ} \mathrm{N}$ off the eastern margin of North America. The Gulf is primarily fed by a relatively fresh inflow from the Scotian Shelf to the north-east, which gets caught in a mean counter clockwise circulation and coastal current. Except for some outflow through the Great South Channel, the bulk of the flow seems to be contained by Georges Bank and exits through the Northeast Channel (Pettigrew et al., 2005) The region supports some of the most fertile fishing grounds, whose productivity is intrinsically tied to the phytoplankton productivity of the Gulf.

Due to its strong influence on fisheries and the environment, the Gulf of Maine is modeled operationally by the University of Maine (Xue et al., 2005), with realistic winds and boundary conditions to produce a daily nowcast of the circulation, temperature and salinity. The circulation model, referred to as GoMPOM, is based on the Princeton Ocean Model; it uses a curvilinear grid with a spatial resolution of approximately $3 \mathrm{~km} \times 3 \mathrm{~km}$ in the horizontal. The model, which is a part of the Gulf of Maine Ocean Observing System (GoMOOS) network, has been rigorously tested with observational data (Xue et al., 2005).

In this study, we use the flow fields from this model for the region shown in Figs. 1-3, saved at 3 hourly intervals for the period 2004-2006. Following this period, the model providing the boundary conditions to GoMPOM was changed. Consequently, post-2006, results from GoMPOM are not entirely consistent with the pervious period, and have not been as rigorously tested and published as those prior to 2006 . Since one of our objectives is to examine the variability over a contiguous period of time extending a few years, we restrict our analysis to the 2004-2006 period.

In what follows, we begin by describing our methods for analyzing satellite data within the context of ocean surface circulation. We then present our productivity estimates based on this methodology, and finally, we discuss the applicability 


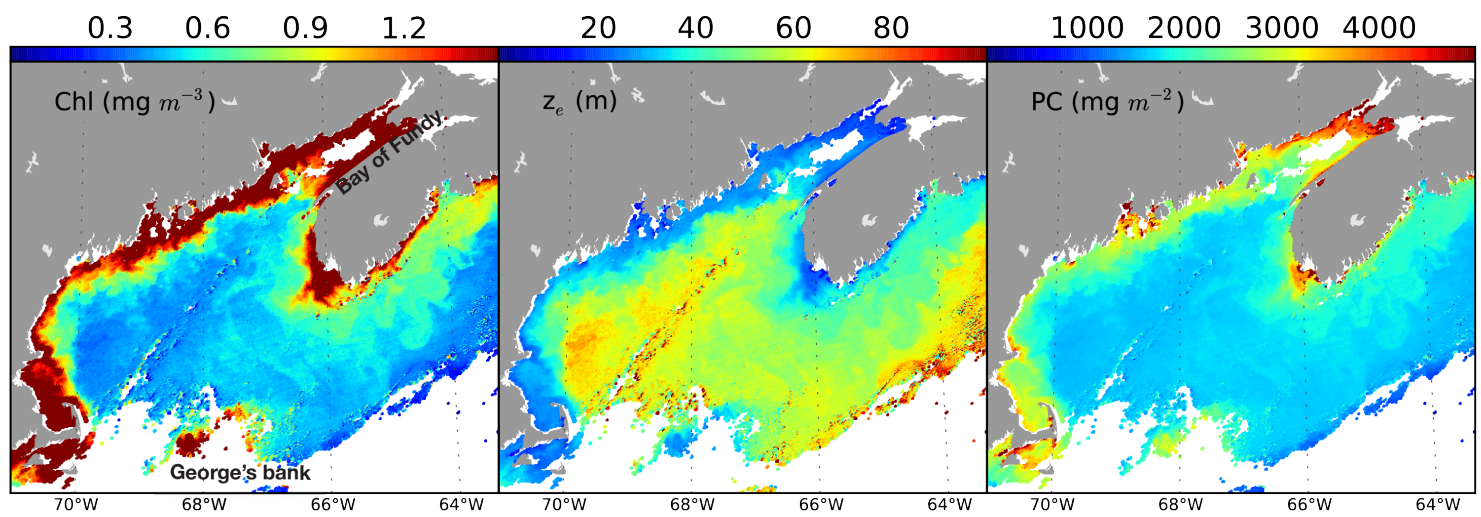

Fig. 1. Left panel shows Chl- $a$ from MODIS Aqua satellite platform on 2 February 2005. The center panel is the euphotic depth $z_{\mathrm{e}}$ at the same time, calculated as $z_{\mathrm{e}}=\log _{\mathrm{e}}(0.01) / K_{490}$ using the MODIS $K_{490}$ fields. In the right panel, PC is calculated using the former fields and a fixed $\mathrm{C}: \mathrm{Chl}$ ratio of 60 as $\mathrm{PC}=\mathrm{Chl}-a \cdot(\mathrm{C}: \mathrm{Chl}) \cdot z_{\mathrm{e}}$. A constant $\mathrm{C}: \mathrm{Chl}$ ratio is used to derive $\mathrm{PC}$ only for the sake of this figure and the next; a dynamic $\mathrm{C}: \mathrm{Chl}$ ratio is used when calculating $\mathrm{NCP}_{\mathrm{e}}$.

of this method to the interpretation of satellite ocean color data in the Gulf of Maine.

\section{Methods}

Our aim is to track the net changes in phytoplankton carbon (PC) integrated over the euphotic depth $\left(z_{\mathrm{e}}\right)$ of the water column. Using the MODIS-Aqua $1 \mathrm{~km} \times 1 \mathrm{~km}$ daily OC- 3 chlorophyll- $a(\mathrm{Chl}-a)$, and the diffuse attenuation coefficient $\left(K_{490}\right)\left[\mathrm{m}^{-1}\right]$ satellite fields, we derive a gross estimate of the vertically integrated Chl- $a$ content as $\overline{\mathrm{Chl}}^{z}=z_{\mathrm{e}} \cdot \mathrm{Chl}$, where $z_{\mathrm{e}}=\log _{\mathrm{e}}(0.01) / K_{490}$ is the euphotic depth to the $1 \%$ light level (Behrenfeld et al., 2005).

The OC-3 Chl- $a$ has been evaluated in the Gulf of Maine by Moore et al. (2009), who determined errors ranging from $16 \%$ for oligotrophic waters to $123 \%$ for high-absorption waters. Based on this work we expect errors in the Chl- $a$ retrievals of $51-68 \%$. The absolute error is somewhat less important in our work since we are differencing data over time (i.e. biases in the satellite retrievals would not affect the NCP results to the degree it would individual determinations). Based on limited data, the MODIS $K_{490}$ product appears to be performing well in the Gulf of Maine.

The assumption is that the satellite $\mathrm{Chl}$ product is representative of the mean $\mathrm{Chl}$ concentration in the euphotic layer, and is furthermore a good proxy for the PC in this layer. We then convert satellite chlorophyll to PC, by employing a carbon:chlorophyll (C:Chl) model that is based on empirical relationships from laboratory studies (Behrenfeld et al., 2005; Geider et al., 1997) but using the change of Chl- $a$ along each trajectory as an estimation of the growth rate (see Appendix for details). It turns out that within the range of surface PAR and temperature for the region, our results are relatively insensitive to the details of this model. Figure 1 shows the PC (hereafter, PC refers to phytoplankton carbon integrated over $\left.z_{\mathrm{e}}\right)$ derived from a single MODIS satellite image, using surface $\mathrm{Chl}$ and the $K_{490}$ attenuation product to determine $z_{\mathrm{e}}$.

Parsing through our repository of MODIS data for the Gulf of Maine, we identify satellite image pairs that have a 26 day separation, which is ideal for resolving phytoplankton growth and allows a reasonably accurate tracing of water parcel trajectories. The PC is calculated for all such image pairs in the 2004-2006 period for which we have model fields.

Our approach is to use the surface velocity fields from the GoMPOM circulation model to track the horizontal movement of euphotic depth-integrated PC derived from the satellite data. This enables us to cast the satellite data in the moving frame of water parcels, and thereby estimate the change in PC due to net growth and respiration. The evolution of PC can be described by

$$
\begin{aligned}
& \frac{D((\mathrm{PC})}{D t}=\frac{\partial(\mathrm{PC})}{\partial t}+\boldsymbol{u} \times \nabla(\mathrm{PC})=+ \text { growth }- \text { respiration } \\
& \quad-\text { grazing }- \text { verticaltransport }=\mathrm{NCP}_{\mathrm{e}},
\end{aligned}
$$

where $\boldsymbol{u}$ is the horizontal velocity of the water and $\nabla(\mathrm{PC})$ the horizontal gradient of PC. The right hand side of the equation represents losses or gains in PC due to biological factors (growth, respiration, grazing), as well as vertical transport (sinking, subduction or dilution). The former set of biological factors would traditionally constitute NCP (Wiliams, 1993) if grazing translated into heterotrophic respiration. Here, we assume that any loss of PC occurring due to vertical transport will be respired or grazed beneath the euphotic layer (Benitez-Nelson et al., 2000; Packard and Christensen, 2004) and may therefore be included in our estimate of $\mathrm{NCP}_{\mathrm{e}}$. We therefore distinguish our estimate, $\mathrm{NCP}_{e}$, from the more traditional definition of NCP by the subscript "e" to denote the inclusion of vertical export from (or entrainment into) the euphotic layer. Admittedly, we have no means to quantify these vertical losses or gains at present and are unable to make a quantitive assessment 


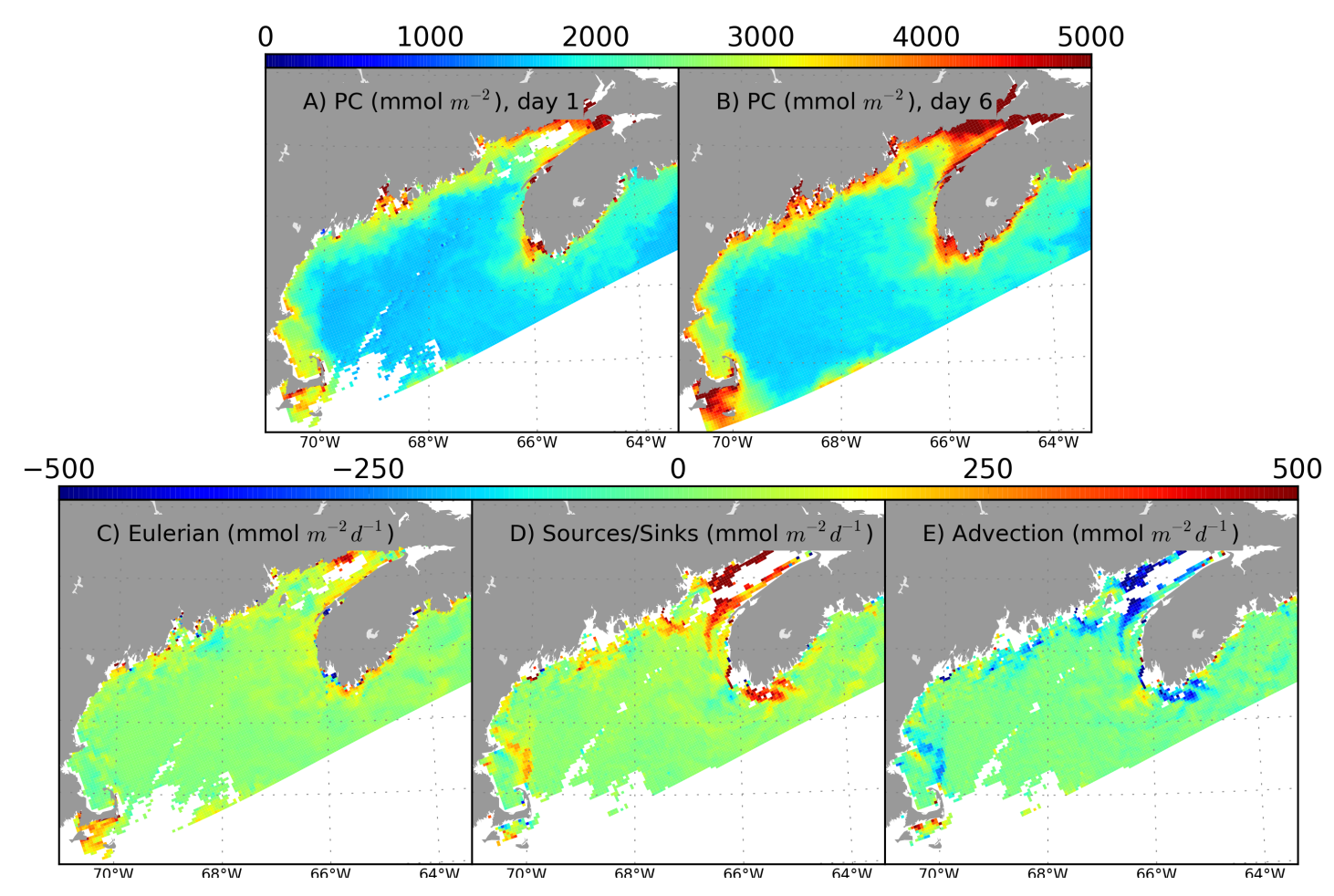

Fig. 2. Panels (a) and (b) show two satellite images from 1 and 6 January 2005, of euphotic depth-integrated Chl- $a$ scaled to PC using a fixed C:Chl ratio of 60. Panel (c) is the (Eulerian) difference calculated by subtracting panel (a) from panel (b), $\partial \mathrm{PC} / \partial t$. Panel (d) shows the difference between the start and end values of PC along water parcel trajectories, i.e. $\partial \mathrm{PC} / \partial t+\boldsymbol{u} \times \nabla$ (PC). These trajectories are computed by seeding particles uniformly in the model flow field and advecting them with surface velocities for the time between the satellite images. They thus represent the source/sink of PC in the moving frame, i.e. $\mathrm{NCP}_{\mathrm{e}}$. Panel (e) represents the advective component of the change. It is that part of (d) that remains after the Eulerian change shown in (c) is subtracted, i.e. $\boldsymbol{u} \times \nabla(\mathrm{PC})$, plotted with a negative sign.

of their contribution. However, other studies (Packard and Christensen, 2004; Charette et al., 2001) have suggested that only a very small fraction of PC produced $(<3 \%$ of NPP) is sequestered in sediments, indicating that a majority of the PC lost is remineralized within in the water column (below $z_{\mathrm{e}}$ ) or exported from the field of study.

To determine $\mathrm{NCP}_{\mathrm{e}}$, we estimate the rate of change of PC following a water parcel trajectory, i.e. the Lagrangian rate of change of satellite-derived PC, denoted by the left hand side of Eq. (1). Water parcel trajectories are calculated by seeding the GoMPOM model domain uniformly with virtual particles to which we attach the PC values from the first of the two satellite images, for each image pair identified. These particles, of which there are several hundred thousand, are advected to new locations using 3-hourly velocities from the model, interpolated in space and time onto the position of the particle, to trace the path of water parcels until the time of the next satellite image (de Vries and Doos, 2001). The change in PC along trajectory, i.e., the difference in value between the starting and ending positions of trajectories obtained from the first and second satellite images (Fig. 2) divided by the time interval between, is the rate of change in $\mathrm{PC}$ along a water parcel trajectory, i.e., $\partial(\mathrm{PC}) / \partial t+\boldsymbol{u} \times \nabla(\mathrm{PC})$. This is calculated on all trajectories for which we can find starting and ending values of PC from the satellite image pair at hand. Details of the Lagrangian particle tracking and the associated errors are discussed in Jönsson et al. (2009). Modeling a very large number of trajectories (several hundred thousand) enables us to obtain reliable statistics that would not be degraded significantly by errors in individual trajectories. The median is used as an estimate of the system-wide, regional, $\mathrm{NCP}_{\mathrm{e}}$ at the time of the satellite image pair so as to eliminate any biasing that might occur due to extreme values. Finally, this procedure is repeated for every time interval for which we have a satellite image pair. This enables us to create a time series of the $\mathrm{NCP}_{\mathrm{e}}$ over the region, which is difficult to obtain by other means.

\section{Results}

At spatial scales $L$ of $10-100 \mathrm{~km}$, the time scale, $L / U$, for horizontal advection by typical surface velocities $U \sim 0.1 \mathrm{~m} \mathrm{~s}^{-1}$ is of order 1-10 days, and is similar to the time scale of net phytoplankton growth. Thus, it would be misleading to deduce biological productivity from temporal 


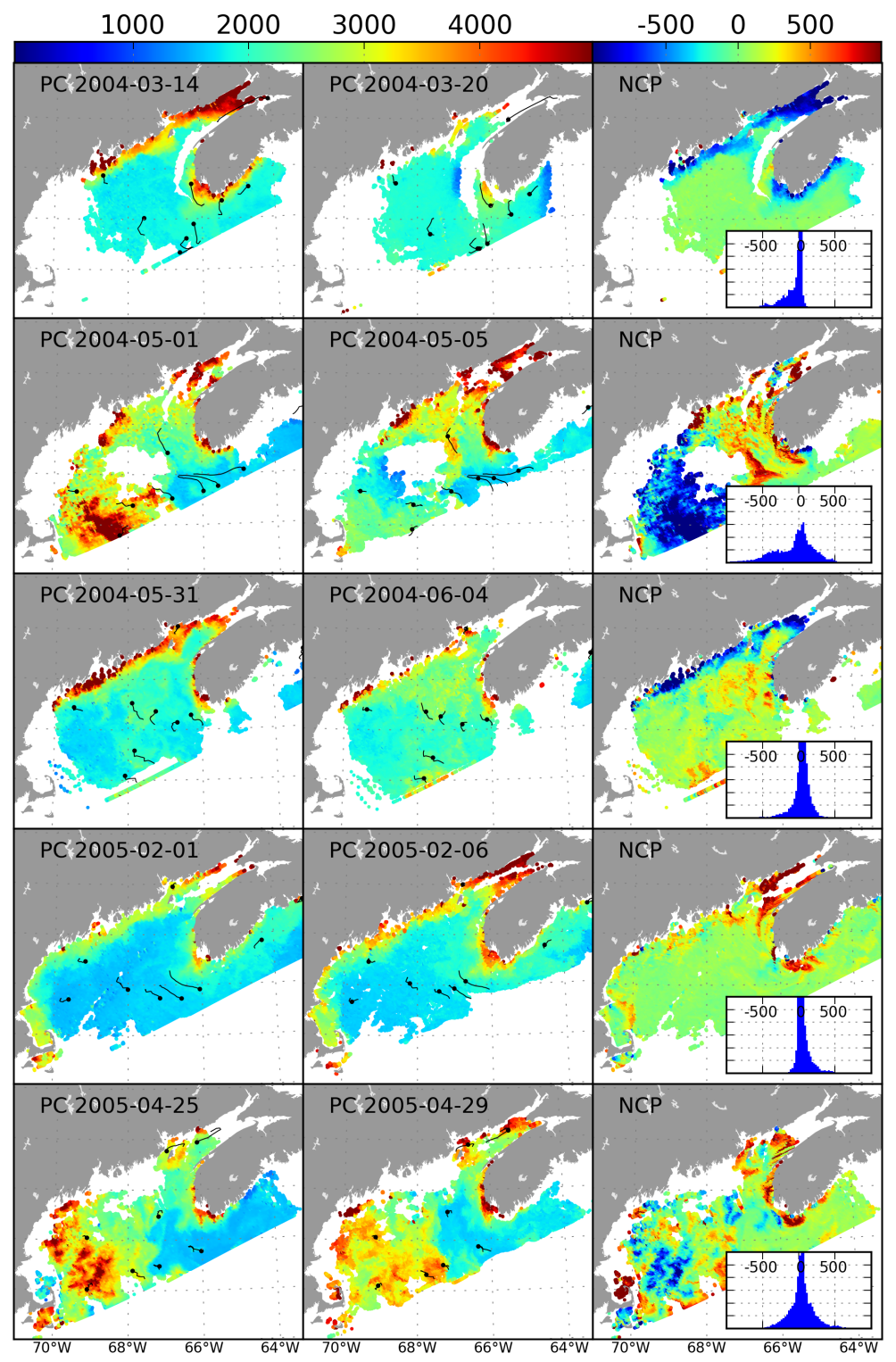

Fig. 3. The growth/consumption of PC $\left(\mathrm{mmol} \mathrm{m}^{-2} \mathrm{~d}^{-1}\right)$ is diagnosed in the reference frame of moving water parcels. PC from the first image at time $t_{1}$ in the left panels is interpolated onto virtual particles whose trajectories are calculated using velocity fields from a circulation model until the time $t_{2}$ of the next satellite image, 4 days later. Each virtual particle, now advected to a new position, finds the value of PC that it should have from the second satellite image. This is plotted in the middle panels at the starting location occupied by the particle. Black lines represent individual trajectories and black dots the position of the particles at the time of the satellite image. The difference, in the right panels, is the net change in PC along-trajectory. For each trajectory, we apply the Chl:C model to derive the net rate of growth/consumption of PC. and then plot the result at the beginning of each trajectory, creating the $\mathrm{NCP}_{\mathrm{e}}$ map. The histograms show the distribution of $\mathrm{NCP}_{\mathrm{e}}$ from all trajectories in each event. The median of all $\mathrm{NCP}_{\mathrm{e}}$ values at a given time constitutes each data point of the time series shown in Fig. 5.

changes of PC observed in a static or Eulerian reference frame. Figure 2a, b shows the PC in the Gulf of Maine estimated from MODIS satellite images at two instances, 1 and 6 January 2005. In both images, PC is high at the coast. The rate of change in PC calculated as the Eulerian difference between these images is shown in Fig. 2c. The Eulerian change is small due to the persistence of spatial pat- terns in PC. A different picture is obtained, however, if one looks at the rate of change of $\mathrm{PC}$ in the moving (Lagrangian) frame of water parcels. In Fig. 2d, we plot the rate of change in PC along water parcel trajectories calculated from velocity fields as described previously. The Lagrangian rate of change, which is equivalent to the $\mathrm{NCP}_{e}$ or the right hand side of Eq. (1), is plotted at the starting position of each 
particle trajectory. Several regions that showed little or no change in the Eulerian frame, now show a positive (negative) value, indicating that the $\mathrm{PC}$ along trajectories leaving these locations increased (decreased) over the span of 5 days. Finally, in Fig. 2e, we plot the difference between the Eulerian rate of change, $\frac{\partial}{\partial t}(\mathrm{PC})$ and the $\mathrm{NCP}_{\mathrm{e}}$, which gives us an estimate of the (negative) advective rate of change, $-\boldsymbol{u} \times \nabla(\mathrm{PC})$ in Eq. (1). Advective losses can be compensated by net production near the coast. Thus, persistence of the $\mathrm{PC}$ or $\mathrm{Chl}$ pattern need not imply that the net productivity or $\mathrm{NCP}_{\mathrm{e}}$ is small.

A similar treatment is applied to each satellite image pair in the 2004-2006 period. In Fig. 3, we show the PC estimated for various image pairs in the February-May time span of this three-year period. The spatial distribution of $\mathrm{PC}$ varies considerably; nearshore values, when available, are generally high, but high values of PC associated with widespread blooms also occur in the south-west part of the domain (the Wilkinson basin). The persistence in PC between the first and second image is also variable. The large bloom in the southwest corner seen on 1 May 2004, for example, is not visible 4 days later. Vertical mixing, leading to dilution, could be the cause for such changes. A few of the trajectories used to calculate the Lagrangian rate of change in $\mathrm{PC}$ (i.e. the $\mathrm{NCP}_{\mathrm{e}}$ ) are shown in the left and middle columns. The streaks denote the trajectories, while dots indicate the position of the water parcel on the given day. The rightmost column in Fig. 3 shows the $\mathrm{NCP}_{\mathrm{e}}$ estimated on individual trajectories plotted at the start position of the trajectories; $\mathrm{NCP}_{\mathrm{e}}$ on all particles within a model grid cell is averaged for plotting. A loss of PC (from the euphotic layer) results in a negative value of $\mathrm{NCP}_{\mathrm{e}}$ as seen for 1 May 2004. On 14 March 2003 and 31 May 2004, high values of PC in the Bay of Fundy and along the coast are lowered once advected offshore along trajectories, resulting in negative $\mathrm{NCP}_{\mathrm{e}}$ in this region. Since the model is tidally forced, the trajectories show elliptical paths over a tidal cycle, and the phase of the tide at the start/end of the trajectory could influence the result nearshore. To analyze the domain-wide statistics from a large number of trajectories, we plot a histogram of the $\mathrm{NCP}_{\mathrm{e}}$ derived for each image pair as shown inset in Fig. 3. The histograms tend to be peaked around zero, i.e. the majority of the trajectories record little or no change in PC. The large spread in the distribution, $\pm 500 \mathrm{mg} \mathrm{m}^{2}$ day $^{-1}$, points to the large spatial variability in the system. The distribution is often asymmetric; the median value of $\mathrm{NCP}_{e}$, which may be positive or negative, is used to construct a time series of $\mathrm{NCP}_{\mathrm{e}}$ for the region.

The satellite images used to create Figs. 1-3 provide nearly complete coverage of the Gulf. However, the Gulf of Maine is often cloudy and satellite coverage is intermittent. Though the satellite passes daily there is oftentimes no coverage, and most available satellite images of the region provide only partial coverage (Fig. 4a). Both the start and end position of the fluid parcel trajectories need necessarily have data for calculating $\mathrm{NCP}_{\mathrm{e}}$. When coverage is partial, the median
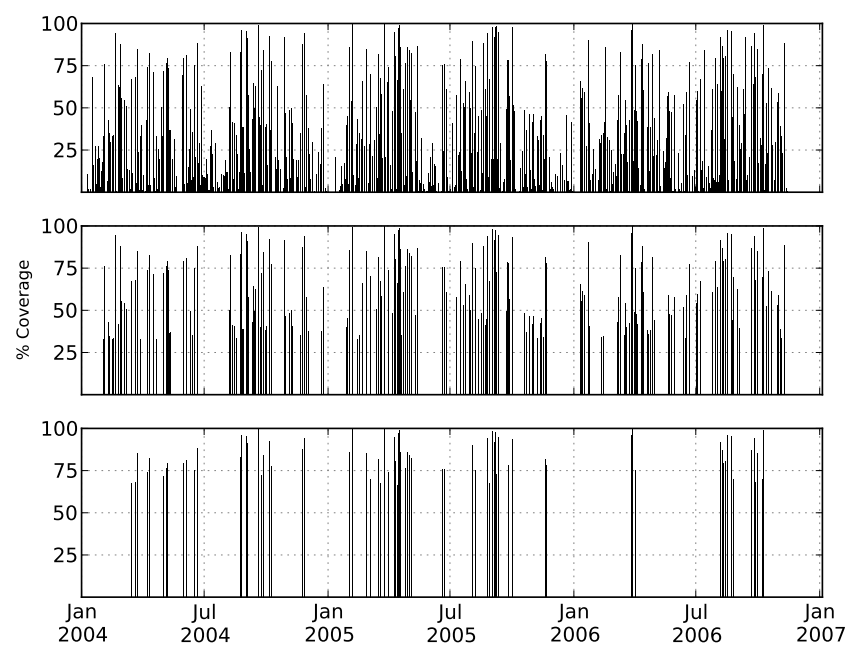

Fig. 4. Precent spatial coverage of MODIS Aqua satellite data in the Gulf of Maine. Top panel shows arial coverage of all satellite images between 2004-2006. In the middle panel, we depict the coverage of image pairs (described earlier), where both images are 2-6 day apart and have at least $30 \%$ arial coverage. The bottom panel is the same as the middle one, but shows images with at least $60 \%$ coverage.

value of $\mathrm{NCP}_{\mathrm{e}}$ for the sub-region with coverage may differ significantly from the $\mathrm{NCP}_{\mathrm{e}}$ of another region, or the median of the entire domain due to the large spatial variability of $\mathrm{NCP}_{\mathrm{e}}$ on scales of $10-100 \mathrm{~km}$ (Fig. 3). Thus, using satellite images with partial arial coverage can be problematic, but restricting our calculations to image pairs with near-complete data coverage or reducing the size of domain, leaves very few data points. It is clear from Fig. $4 \mathrm{~b}-\mathrm{c}$, which shows events with coverage exceeding $30 \%$ and $60 \%$ respectively, that restricting the data to have a certain minimal arial coverage greatly reduces the temporal resolution of the time series that we aim to construct with these data.

One of the objectives of this work is to examine the temporal variability of $\mathrm{NCP}_{\mathrm{e}}$ in this continental shelf region. When we plot the median $\mathrm{NCP}_{\mathrm{e}}$ of all available trajectories identified during the period 2004-2006 (Fig. 5a), we find a significant variability in these estimates due to the large spatio-temporal variability of productivity in this region. The region-wide $\mathrm{NCP}_{\mathrm{e}}$ (points constructed with $>50 \%$ coverage) shows large variations over the 7-10 day time scale, probably in response to bloom events in the spring and fall. Such event-based variability exceeds the seasonal variations in the region-wide $\mathrm{NCP}_{\mathrm{e}}$. Some peaks in the $\mathrm{NCP}_{\mathrm{e}}$ time series in 2005-2006 are coincident with peaks in the terrestrial discharge hydrograph (http://waterdata.usgs.gov/ $\mathrm{me} / \mathrm{nwis} / \mathrm{rt}$ ), suggesting that storms may precipitate bloom events, perhaps due to changes in stratification or nutrient status. Extreme high values in the $\mathrm{NCP}_{\mathrm{e}}$ are sometimes preceded by extreme low values of $\mathrm{NCP}_{\mathrm{e}}$ (e.g. spring 2005) that follow from a region-wide decline and increase in Chl- $a$. We 


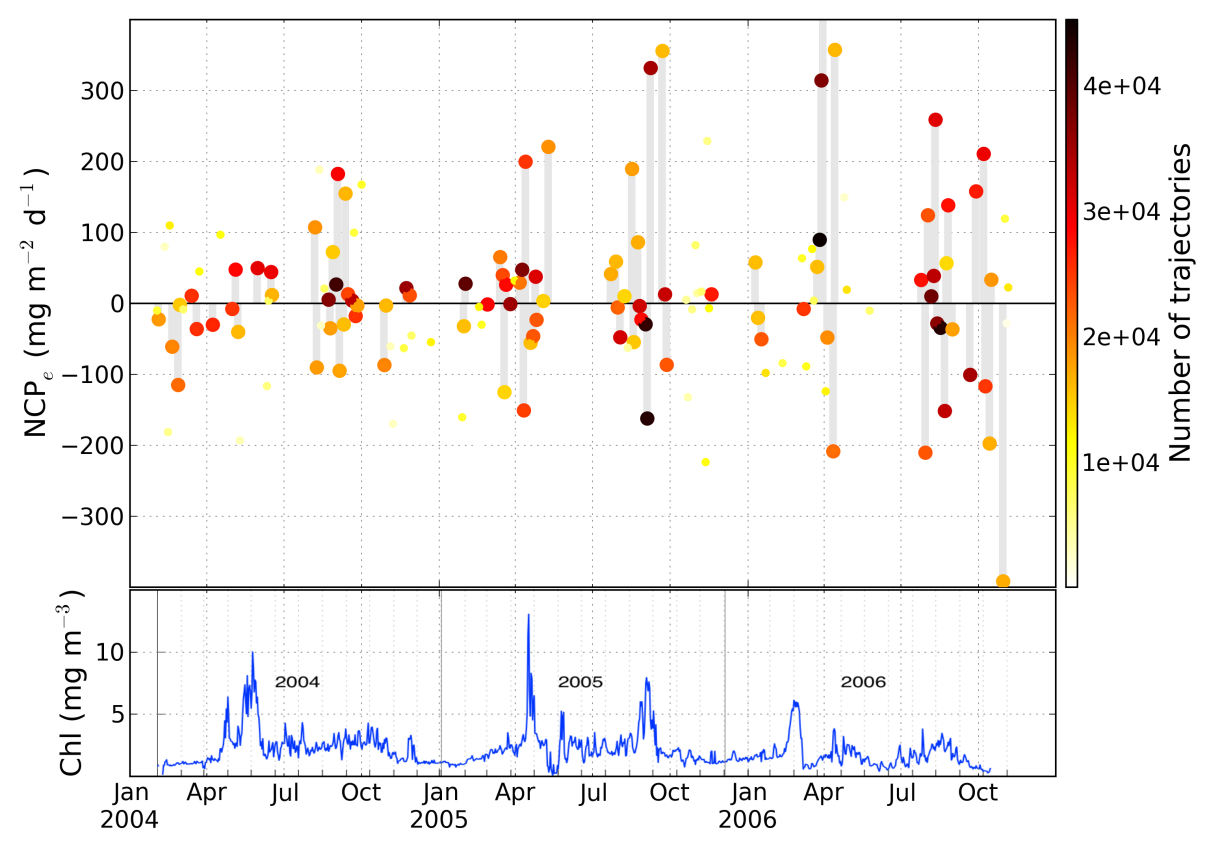

Fig. 5. The upper panel shows the region-wide median $\mathrm{NCP}_{\mathrm{e}}$ values calculated from a number of satellite image pairs for 2004-2006. The color of each point indicates the number of trajectories used for creating the estimate. Values based on more than $50 \%$ of potentially available trajectories are denoted by grey bars. Points without a grey bar are based on satellite images with partial coverage of the Gulf, and therefore they tend to represent a local region of the Gulf, rather than the full area. The lower panel shows the median value of the surface chlorophyll recorded by the four GoMOOS (Pettigrew et al., 2008) buoys A, B, E, and I. Large NCPe events diagnosed from the satellite-model analysis are followed by an increase in surface $\mathrm{Chl}$ recorded by buoys.

hypothesize that this results from increased vertical mixing and entrainment into the surface layer, which first leads to the dilution of surface $\mathrm{Chl}$, followed by the blooming of phytoplankton due to an enhancement in surface nutrients. A rapid increase in the region-wide $\mathrm{NCP}_{\mathrm{e}}$ diagnosed from satellite is often correlated with blooming events recorded by buoys in the region (Fig. 5b).

To look for persistent spatial patterns in the distribution of $\mathrm{NCP}_{e}$, we plot the median of the $\mathrm{NCP}_{e}$ at each location over the three-year period (Fig. 6a). Though the mean phytoplankton carbon (PC) distribution based on satellite Chl- $a$ displays high values along the coast, $\mathrm{NCP}_{\mathrm{e}}$ values may be positive or negative according to whether waters leaving that position exhibit an increase or decline of phytoplankton carbon (PC) stock. The resulting pattern is hence influenced by the underlying circulation pattern in the Gulf (shown as black arrows, adopted from Pettigrew et al. (2005). We contrast this view of the median $\mathrm{NCP}_{\mathrm{e}}$ distribution with that of median NPP (Fig. 6b) derived from the VGPM algorithm (Behrenfeld and Falkowski, 1997) for the same time period as the NCP. Regions close to the coast are highly productive in general, but the lateral transport of these productive waters away from the coast, and the decline in their PC concentration as they are advected, results in low $\mathrm{NCP}_{\mathrm{e}}$ along the coastline.

Regions to the south and west of the Scotian Shelf are enhanced with nutrients entering through the Northeast chan- nel and continue to be productive as they leave the region. Waters south of Maine are productive, but their nutrients are exhausted and they show a decrease in PC as they are advected away. An enhancement in phythoplankton biomass is evident north of Cape Cod. The highly productive Georges Bank is not a part of this domain, but lies just to the south of the open boundary. Another way to think of this, assuming that PC stock remains more or less unchanged in time, is that regions with positive $\mathrm{NCP}_{\mathrm{e}}$ are importing $\mathrm{PC}$, while those with negative $\mathrm{NCP}_{e}$ are exporting PC from surrounding areas. The range in the mean $\mathrm{NCP}_{\mathrm{e}}$ values shown here is smaller by a factor of 10 than the $\mathrm{NCP}_{\mathrm{e}}$ values computed for a given snapshot in time, and thus, the temporal variations are much larger than the mean itself.

\section{Discussion}

We present results from a new method for estimating phytoplankton productivity from remotely sensed data in a coastal environment. Our method estimates the net change in PC from sequential satellite images, as compared to other methods that empirically model growth based on state variables derived from a satellite image. The delineation of the temporal and spatial variability over days and tens of kilometers, and the synoptic view offered through such analyses, makes them highly attractive. Further, the interpretation of satellite 


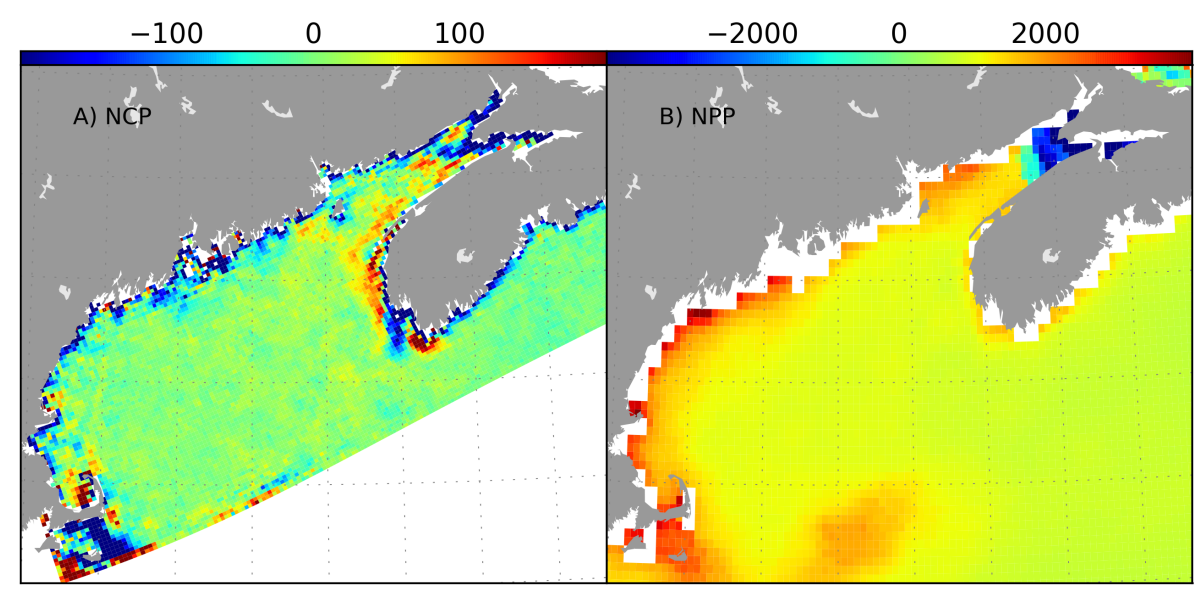

Fig. 6. Panel (A) shows the three year (2004-2006) median of $\mathrm{NCP}_{\mathrm{e}}$ for the Gulf of Maine, calculated using the method described in Sect. 2. Panel (B) shows Net Primary Production (NPP) calculated using the VGPM algorithm (Behrenfeld and Falkowski, 1997) for the equivalent time span.

data in a dynamic framework using ocean model fields, offers further scope for measuring net changes.

In this study, we have tracked phytoplankton carbon (PC), the photosynthetically active part of the carbon pool, derived from satellite data. We emphasize that PC refers to the carbon associated with phytoplankton cells and does not include detritus or other particulate forms that are often included in other satellite based ocean color products of POC (Behrenfeld and Boss, 2003, 2006; Gardner et al., 2001). We find, in fact, that a particle backscatter ( $\left.b_{\mathrm{bp}}\right)$-based estimate of euphotic-depth integrated POC is not reliable in the Gulf of Maine, possibly because it is a coastal region with strong tidal mixing and sediment resuspension. Losses of PC occurring via heterotrophy (e.g. grazing, microbial consumption) contribute to our estimate of $\mathrm{NCP}_{\mathrm{e}}$, even though grazing can result in a conversion of PC to other forms of POC. A remineralization-associated loss of $\mathrm{POC}$ is representative of community respiration, but losses that arise from sinking of larger particles can be much more significant in the case of POC than PC.

Another error term in our satellite-based estimates of $\mathrm{NCP}_{e}$ arises from our inability to resolve carbon lost from extracellular release of DOC during autotrophy, the production of calcium carbonate, and heterotrophic production of refractory dissolved organic carbon. Data from the Gulf of Maine show that extracellular release of DOC averaged over all seasons is approximately $10-15 \%$ of net carbon production (Mague et al., 1980; O'Reilly and Busch, 1984). While others have reported higher values e.g. (Moran et al., 2002), work in this area strongly suggests that rates are highest during times of nutrient limitation (Lancelot, 1983; Mague et al., 1980). This would mean that rates are highest when little carbon is being fixed. As such, we would not seriously compromise estimates of $\mathrm{NCP}_{e}$ during high productivity events by not accounting for extracellular release. Further, we as- sume nearly all of the DOC produced by seasonal autotrophic and heterotrophic processes is labile and is respired on subannual time scales. We find little consensus on the timescales of its remineralization rate in coastal waters. However, if refractory DOC is produced in significant amounts in the coastal environment, it represents an uncharacterized error term in our estimates of $\mathrm{NCP}_{\mathrm{e}}$ that could result in the export of carbon Hopkinson and Vallino (1995). The production of suspended calcium carbonate, likely averaging $<5 \%$ of total carbon production (Balch et al., 2008; Graziano et al., 2000), is also not accounted for. DOC can also be a potential source of error in the form of CDOM, which can interfere with the Chl signal. The coastal Gulf of Maine is known to have high CDOM absorption values (Balch et al., 2008). CDOM absorption at lower wavelengths will typically cause a high bias in chlorophyll estimates. We believer that this effect is limited on the timescales of importance (changes in Chl concentration on the order of 1-6 days) for our study, but this should be examined further.

Our estimate of $\mathrm{NCP}_{\mathrm{e}}$ includes the vertical flux of PC into or out of the euphotic layer. Since PC is associated with living phytoplankton cells, sinking losses are small. Vertical export of PC from the euphotic zone occurs via subduction and mixing, or a deepening of the mixed layer that leads to the dilution of PC in the euphotic layer. One could argue that PC leaving the euphotic zone is remineralized beneath, either directly or via grazing, and only a negligibly small fraction gets sequestered in the sediment. Thus, inclusion of vertical export of PC in our estimate of $\mathrm{NCP}_{\mathrm{e}}$ may be logical, but the loss of PC due to vertical processes and its remineralization, may be separated by a few days. A large mixing event such as a storm, could lead to the entrainment of nutrients into the euphotic layer, which would result in production of phytoplankton and positive $\mathrm{NCP}_{\mathrm{e}}$. Vertical mixing could also dilute the concentration of phytoplankton in the euphotic layer 
and contribute to a negative $\mathrm{NCP}_{\mathrm{e}}$. When the mixed layer is shallow, and PC is present subsurface of the ML, a mixing event could increase surface PC due to entrainment of the subsurface bloom. Using satellite data, we address only the horizontal transport of PC integrated over the euphotic layer. Its redistribution in the vertical is difficult to assess and needs to be addressed further in future work.

In a time integrated sense, the NCP of a region is indicative of its potential to export carbon. Our estimate of $\mathrm{NCP}_{e}$ (Fig. 5) is highly variable and not always inclusive of the entire region. However, the data points at hand tend to integratively suggest a net positive $\mathrm{NCP}_{\mathrm{e}}$ in the region, which would imply an export of carbon. In two previous studies that used ${ }^{234}$ Thorium, POC export from the Gulf of Maine was estimated at $180-408 \mathrm{mg} \mathrm{C} \mathrm{m}^{-2}$ day $^{-1}$ (Charette et al., 2001) and $74-173 \mathrm{mg} \mathrm{C} \mathrm{m}^{-2}$ day $^{-1}$ (Benitez-Nelson et al., 2000) over a few weeks. In contrast, primary production was estimated as $355 \mathrm{mg} \mathrm{C} \mathrm{m}^{-2} \mathrm{day}^{-1}$ (Charette et al., 2001) and $794 \mathrm{mg} \mathrm{C} \mathrm{m}^{-2}$ day $^{-1}$ (O'Reilly and Busch, 1984). A large, though variable, export of PC that is suggested to occur via lateral transport in our analysis, could help to account for the missing carbon that is postulated to leave the continental shelves (Walsh et al., 1981), but remains unaccounted for in POC fluxes measured via sediment traps in the middle-to-lower water column. It is notable that the $\mathrm{NCP}_{\mathrm{e}}$, and thus, export of PC, can exhibit larger inter-annual variability than the PC stock itself. Measurement of surface $p \mathrm{CO}_{2}$ along a repeated monthly cross-shelf ship transect, though limited in coverage, also finds the sea-to-air flux of $\mathrm{CO}_{2}$ to be highly variable. It is estimated as $+16,-40.1$, $+12.2 \mathrm{mg} \mathrm{C} \mathrm{m}^{-2} \mathrm{day}^{-1}$ averaged over the years 2004, 2005, and 2006, respectively (Salisbury et al., 2009).

\section{Conclusions}

Our method of tracking satellite derived PC with model velocity fields enables us to diagnose the net production of PC in the euphotic layer $\left(\mathrm{NCP}_{\mathrm{e}}\right)$ from sequential satellite images. The high spatio-temporal complexity of a continental shelf region uncovered by our methodology underscores the need for space- and time-resolving estimation and monitoring of the continental shelf carbon budgets. The greatest variability in $\mathrm{NCP}_{\mathrm{e}}$ is driven by events lasting a few ( $<10$ days) when $\mathrm{NCP}_{\mathrm{e}}$ attains values as high as $400 \mathrm{mg} \mathrm{C} \mathrm{m}^{-2} \mathrm{~d}^{-1}$. Highly productive regions can exhibit both positive and negative $\mathrm{NCP}_{\mathrm{e}}$. The large and highly variable $\mathrm{NCP}_{\mathrm{e}}$ implies a significant lateral flux of phytoplankton biomass and points to the need for incorporating such fluxes into the lateral boundary conditions of global carbon cycle models. In nearshore regions, a high PC concentration is often coincident with a negative value of $\mathrm{NCP}_{\mathrm{e}}$, indicative that these regions are exporting their production of PC to offshore waters. A better understanding of factors controlling such fluxes of carbon, as well as nutrients, is needed to link continental and oceanic biogeochemistry and improve global carbon budgets.

\section{Appendix A}

The ratio of chlorophyll to carbon $(\Theta)$ in phytoplankton can vary due to physiological acclimation. We use a Chl:C model (Behrenfeld et al., 2005) that is based on empirical relationships (Laws and Bannister, 1980; Cloern et al., 1995b; Geider et al., 1997, 1998), but is adapted to using satellitederived variables, which lack information about nutrient limitation or phytoplankton growth rate. $\Theta$ is calculated as (Behrenfeld et al., 2005)

$\Theta=\Theta_{\min }+\left(\Theta_{\max }-\Theta_{\min }\right) e^{-3 I_{g}}$,

where $\Theta_{\max }$ is the low-light maximum that increases with temperature $(T)$, and $\Theta_{\min }$ is a light-saturated minimum that decreases with nutrient stress. We estimate irradiance $I_{g}$ (mol photons $\mathrm{m}^{-2} \mathrm{~h}^{-1}$ ) from a climatological model, and temperature $T\left({ }^{\circ} \mathrm{C}\right)$ from the SST product provided by MODIS. The dependence of $\Theta_{\max }$ on $T$ is described by

$\Theta_{\max }=0.0155+0.00005 \cdot e^{0.215 T}$.

Instead of basing $\Theta_{\min }$ on $T$ (Behrenfeld et al., 2005), which may not be ideal near-coast where nutrient stress and temperature are poorly correlated, we exploit the Chl- $a$ growth rate that is diagnosed by our model for each particle trajectory, and estimate $\Theta_{\min }$ from the regression based on growth rate $(\mu)$ (Laws and Bannister, 1980)

$\Theta_{\min }=\frac{1.14+15.1 \mu}{1000}$.

We approximate the growth rate $\mu\left(\mathrm{day}^{-1}\right)$ by the absolute value of the rate of change of Chl- $a$ normalized by its original level along a trajectory, which we term $\gamma$, i.e., $\gamma=\left|\frac{1}{\operatorname{Chl}-a} \cdot \frac{D}{D t}(\mathrm{Chl}-a)\right|$, for each particle in the study. The difference between $\gamma$ (which replaces $\mu$ in the above equation) and $\mu$ is that $\gamma$ has the likeness of $\mathrm{NCP}_{\mathrm{e}}$, in that it derives from the net change in Chl- $a$ (though we take the positive value), whereas $\mu$ has the likeness of NPP (net primary productivity). We are assuming that rapid decay is likely to result when there has been rapid growth, and hence both growth and decay of Chl- $a$ may have the same $\gamma$. Since $\gamma$ represents net growth, it may under-estimate the growth rate $\mu$. However, our sensitivity studies show that a five-fold increase in $\gamma$ (which is a representative maximum ratio of NPP to $\mathrm{NCP}_{\mathrm{e}}$ in this region) changes the mean $\Theta$ only from 0.017 to 0.023 , with most of the difference occurring in very few extreme events. The correlation between $\mu$ and $\Theta_{\min }$ was developed for Thalassiora fluviatilis, but seems to be consistent with other studies for different groups of phytoplankton (Cloern et al., 1995a). 
Acknowledgements. We thank Huijie Xue and Steve Cousins at $\mathrm{U}$. Maine for generously providing operational model velocity fields, and Tim Moore at the UNH for satellite fields. The authors were supported by the NOAA-UNH Joint Center (NOAA award NA16OC2740) and by NASA (NNH07ZDA001N-Carbon).

Edited by: M. Dai

\section{References}

Arthur, C.-T. and Borges, A. V.: Reconciling opposing views on carbon cycling in the coastal ocean: Continental shelves as sinks and near-shore ecosystems as sources of atmospheric $\mathrm{CO}_{2}$, Deep-Sea Res. Pt. II, 56, 578-590, 2009.

Balch, W. M., Drapeau, D. T., Bowler, B. C., Booth, E. S., Windecker, L. A., and Ashe, A.: Space-time variability of carbon standing stocks and fixation rates in the Gulf of Maine, along the GNATS transect between Portland, ME, USA, and Yarmouth, Nova Scotia, Canada, J. Plankton Res., 30, 119-139, doi:10.1093/plankt/fbm097, 2008.

Behrenfeld, M. and Boss, E.: The beam attenuation to chlorophyll ratio: an optical index of phytoplankton photoacclimation in the surface ocean?, Deep-Sea Res. Pt. I, 50, 1537-1549, 2003.

Behrenfeld, M. J.: Abandoning Sverdrup's Critical Depth Hypothesis on phytoplankton blooms, Ecology, 91, 977-989, 2010.

Behrenfeld, M. J. and Boss, E.: Beam attenuation and chlorophyll concentration as alternative optical indices of phytoplankton biomass, J. Mar. Res., 64, 431-451, 2006.

Behrenfeld, M. J. and Falkowski, P. G.: A consumer's guide to phytoplankton primary productivity models, Limnol. Oceanogr., 42, 1479-1491, 1997.

Behrenfeld, M. J., Boss, E., Siegel, D. A., and Shea, D. M.: Carbon-based ocean productivity and phytoplankton physiology from space, Global Biogeochem. Cy., 19, GB1006, doi:10.1029/2004GB002299, 2005.

Benitez-Nelson, C. R., Buesseler, K. O., and Crossin., G.: Upper ocean carbon export, horizontal transport, and vertical eddy difusivity in the southwestern Gulf of Maine, Cont. Shelf Res., 20, 707-736, doi:10.1016/S0278-4343(99)00093-X, 2000.

Borges, A. V. and Frankignoulle, M.: Distribution of surface carbon dioxide and air-sea exchange in the upwelling system off the Galician coast, Global Biogeochem. Cy., 16, 1020, doi:10.1029/2000GB001385, 2002.

Cai, W. J., Wang, Z. H. A., and Wang, Y. C.: The role of marshdominated heterotrophic continental margins in transport of $\mathrm{CO}_{2}$ between the atmosphere, the land-sea interface and the ocean, Geophys. Res. Lett., 30, 1849, doi:10.1029/2003GL017633, 2003.

Charette, M. A., Moran, S. B., Pike, S. M., and Smith, J. N.: Investigating the carbon cycle in the Gulf of Maine using the natural tracer thorium 234, J. Geophys. Res., 106, 11553-11579, 2001.

Cloern, J., Grenz, C., and Vidergar-Lucas, L.: An empirical model of the phytoplankton chlorophyllcarbon ratio - The conversion factor between productivity and growth rate, Limnol. Oceanogr., 40, 1313-1321, 1995a.

Cloern, J. E., Grenz, C., and Vidergar-Lucas, L.: An empirical model of the phytoplankton chlorophyll:carbon ratio - The conversion factor between productivity and growth rate, Limnol. Oceanogr., 40, 1313-1321, 1995b.
Craig, H. and Hayward, T.: Oxygen Supersaturation in the Ocean: Biological Versus Physical Contributions, Science, 235, 199202, doi:10.1126/science.235.4785.199, 1987.

de Vries, P. and Doos, K.: Calculating Lagrangian trajectories using time-dependent velocity fields, J. Atmos. Ocean. Tech., 18, 1092-1101, 2001.

Frankignoulle, M., Abril, G., Borges, A., Bourge, I., Canon, C., DeLille, B., Libert, E., and Theate, J. M.: Carbon dioxide emission from European estuaries, Science, 282, 434-436, 1998.

Gardner, W. D., Blakey, J. C., Walsh, I. D., Richardson, M. J., Pegau, S., Zaneveld, J. R. V., Roesler, C., Gregg, M. C., MacKinnon, J. A., Sosik, H. M., and Williams, A. J.: Optics, particles, stratification, and storms on the New England continental shelf, J. Geophys. Res., 106, 9473-9497, 2001.

Gattuso, J. P., Frankignoulle, M., and Wollast, R.: Carbon and carbonate metabolism in coastal aquatic ecosystems, Annu. Rev. Ecol. Syst., 29, 405-434, 1998.

Geider, R., MacIntyre, H., and Kana, T.: Dynamic model of phytoplankton growth and acclimation: Responses of the balanced growth rate and the chlorophyll a:carbon ratio to light, nutrientlimitation and temperature, Mar. Ecol.-Prog. Ser., 148, 187-200, 1997.

Geider, R., MacIntyre, H., and Kana, T.: A dynamic regulatory model of phytoplanktonic acclimation to light, nutrients, and temperature, Limnol. Oceanogr., 43, 679-694, 1998.

Graziano, L. M., Balch, W. M., Drapeau, D., Bowler, B. C., Vaillancourt, R., and Dunford, S.: Organic and inorganic carbon production in the Gulf of Maine, Cont. Shelf Res., 20, 685-705, 2000.

Hopkinson, C. and Vallino, J.: The Relationships Among Mans Activities in Watersheds and Estuaries - a Model of Runoff Effects on Patterns of Estuarine Community Metabolism, Estuaries, 18, 598-621, 1995.

Jönsson, B. F., Salisbury, J. E., and Mahadevan, A.: Extending the Use and Interpretation of Ocean Satellite Data Using Lagrangian Modeling, Int. J. Remote Sens., 30, 3331-3341, doi:10.1080/01431160802558758, 2009.

Kaiser, J., Reuer, M., Barnett, B., and Bender, M.: Marine productivity estimates from continuous $\mathrm{O}-2 / \mathrm{Ar}$ ratio measurements by membrane inlet mass spectrometry, Geophys. Res. Lett., 32, L19605, doi:10.1029/2005GL023459, 2005.

Kortzinger, A.: A significant $\mathrm{CO}_{2}$ sink in the tropical Atlantic Ocean associated with the Amazon River plume, Geophys. Res. Lett., 30, 2287, doi:10.1029/2003GL018841, 2003.

Lancelot, C.: Factors Affecting Phytoplankton Extracellular Release in the Southern Bight of the North-Sea, Mar. Ecol.-Prog. Ser., 12, 115-121, 1983.

Langdon, C., Marra, J., and Knudson, C.: Measurments of Net and Gross $\mathrm{O}_{2}$ Production, Dark $\mathrm{O}_{2}$ Respiration, and ${ }^{14} \mathrm{C}$ Assimialtion at the Marine Light-Mixed Layers Site $\left(59^{\circ} \mathrm{N}, 21^{\circ} \mathrm{W}\right)$ in the Northeast Atlantic-Ocean, J. Geophys. Res.-Oceans, 100, 66456653, 1995.

Laws, E. A. and Bannister, T. T.: Nutrient- and light-limited growth of Thalassiosira fluviatilis in continuous culture with implications for phytoplankton growth in the ocean, Limnol. Oceanogr., 25, 457-473, 1980.

Mague, T., Friberg, E., Hughes, D., and Morris, I.: Extracellular Release of Carbon by Marine-Phytoplankton - a Physiological Approach, Limnol. Oceanogr., 25, 262-279, 1980. 
Marra, J., Chamberlin, W., and Knudson, C.: Proportionality Between Insitu Carbon Assimilation and Biooptical Measures of Primary Production in the Gulf of Maine in Summer, Limnol. Oceanogr., 38(1), 232-238, 1993.

Moore, T., Campbell, J., and Dowell, M.: A class-based approach to characterizing and mapping the uncertainty of the MODIS ocean chlorophyll product, Remote Sens. Environ., 113, 2424-2430, 2009.

Moran, X. A. G., Gasol, J. M., Pedros-Alio, C., and Estrada, M.: Partitioning of phytoplanktonic organic carbon production and bacterial production along a coastal-offshore gradient in the NE Atlantic during different hydrographic regimes, Aquat. Microb. Ecol., 29, 239-252, 2002.

O'Reilly, J. and Busch, D.: Phytoplankton primary production on the northwestern Atlantic Shelf, Rapport P.-v. Reun. Cons. Int. Explor. Mer., 255-268, 1984.

Packard, T. T. and Christensen, J. P.: Respiration and vertical carbon flux in the Gulf of Maine water column, J. Mar. Res., 62, 93-115, 2004.

Pettigrew, N. R., Churchill, J. H., Janzen, C. D., Mangum, L. J., Signell, R. P., Thomas, A. C., Townsend, D. W., Wallinga, J. P., and Xue, H. J.: The kinematic and hydrographic structure of the Gulf of Maine Coastal Current, Deep-Sea Res. Pt. II, 52, 23692391, 2005.

Pettigrew, N. R., Roesler, C., and Irish, J. D.: GoMOOS Environmental Data Reporting System, http://www.gomoos.org, 2008.
Salisbury, J., Mahadevan, A., Jönsson, B., Vandemark, D., Hunt, C., and McGillis, W.: Episodic riverine influence on surface DIC in the coastal Gulf of Maine, Estuar. Coast. Shelf S., 82, 108-118, 2009.

Tsunogai, S., Watanabe, S., and Sato, T.: Is there a "continental shelf pump" for the absorption of atmospheric $\mathrm{CO}_{2}$ ?, Tellus B, 51, 701-712, 1999.

Walsh, J., Rowe, G., Iverson, R., and McRoy, C.: Biological export of shelf carbon is a sink of the global $\mathrm{CO}_{2}$ cycle, Nature, 291, 196-201, 1981.

Williams, P. and Purdie, D.: In vitro and in situ derived rates of gross production, net community production and respiration of oxygen in the oligotrophic subtropical gyre of the North Pacific Ocean, Deep-Sea Res. Pt. II, 38, 891-910, doi:10.1016/01980149(91)90024-A, 1991.

Wiliams, P. J. L.: On the Definition of Plankton Production Terms, in: Measurement of Primary Production from the Molecular to the Global Scale, edited by: Li, W. K. W. and Maestrini, S. Y., vol. 197 of ICES Marine Science Symposia, ICES, 9-19, 1993.

Xue, H. J., Shi, L., Cousins, S., and Pettigrew, N. R.: The GoMOOS nowcast/forecast system, Cont. Shelf Res., 25, 2122-2146, 2005.

Zhai, L., Platt, T., Tang, C., Dowd, M., Sathyendranath, S., and Forget, M.-H.: Estimation of phytoplankton loss rate by remote sensing, Geophys. Res. Lett., 35, L23606, doi:10.1029/2008GL035666, 2008. 